\title{
COLÓQUIO SOBRE CASAS SUBTERRÂNEAS
}

\section{O I COLÓQUIO SOBRE SÍTIOS CONSTRUÍDOS: CASAS SUBTERRÂNEAS realizou-se no período de 15 e 16 de agosto de} 2002, na cidade de Santa Maria (RS). O evento foi organizado pelo Prof. Dr. Saul Eduardo Seiguer Milder, coordenador do Laboratório de Estudos e Pesquisas Arqueológicas (LEPA) da Universidade Federal de Santa Maria.

Participaram do colóquio arqueólogos que atuam nos estados do Rio Grande do Sul, Santa Catarina e São Paulo de diversas instituições desenvolvendo pesquisas de campo em casas subterrâneas. As comunicações foram apresentadas por: Marisa Afonso Coutinho, Luciane Miwa Kamase (Museu de Arqueologia e Etnologia/USP); Marco Aurélio Nadal De Masi (UNISUL); Silvia Moehleke Copé (Núcleo de Pesquisas Arqueológicas, UFRGS); Neli T. Galarce Machado (Setor de Arqueologia, UNIVATES); Saul Eduardo Seiguer Milder (Laboratório de Estudos e Pesquisas Arqueológicas, UFSM); Pedro Ignacio Schmitz, Jairo Henrique Rogge, Glória Demamman (Instituto Anchietano de Pesquisas, UNISINOS) e Ana Lucia Herberts (Scientia Ambiental).

Estiveram presentes também integrantes das equipes da UFSM, UNIVATES, IAP/UNISINOS, UFRGS, Laboratório de Estudos e Pesquisas Arqueológicas e Antropológicas da Universidade Federal de Pelotas (RS), com seu coodenador, Prof. Dr. Fabio Vergara, Núcleo de Estudos de Arqueologia da Universidade de Chapecó (SC), entre outros.

As casas subterrâneas são um tipo de sítio arqueológico caracterizado por crateras abertas no solo, de diversos tamanhos, entre 2 e $20 \mathrm{~m}$ de diâmetro e até $6 \mathrm{~m}$ de profundidade, e formatos entre circular e elíptico. Sua ocorrência é raramente de forma isolada, sendo que esses agrupamentos também apresentam variação de tamanho entre as unidades. Em algumas delas foram observadas evidências de postes que sustentavam o teto das casas e no fundo foram encontrados fogões de pedra com pinhões calcinados, com presença de carvões vegetais, fragmentos cerâmicos e artefatos líticos.

Em geral, esse tipo de sítio está associado a altitudes superiores de $400 \mathrm{~m}$ e regiões de clima rigoroso. Acredita-se que essas depressões serviriam como abrigos do frio e até mesmo para habitação.
O tema casas subterrâneas tem sido alvo de estudos desde a década de 1960 com maior intensidade nos estados da região Sul e algumas ocorrências nos estados de Minas Gerais e São Paulo. Particularmente no território paulista, o tema havia ficado à margem das discussões arqueológicas, sendo a única fonte de referência $o$ artigo escrito por André Prous (Prous 1979) que trata de casas subterrâneas descobertas nas proximidades de Itararé, sudeste do estado de São Paulo. Depois disso, somente no final dos anos de 1990, foram localizadas outras casas subterrâneas, no entanto, esses achados nunca foram publicados, estão em relatório de salvamento (Afonso 1997; De Blasis 2000) ou fazem parte de produções acadêmicas (Araujo 1995, 2001).

Atualmente, Luciane Kamase (Kamase 2001) tem desenvolvido o projeto de mestrado na região de Itapeva (sudeste do estado de São Paulo), sob orientação de Marisa Afonso e financiada pela FAPESP, tratando especificamente do aspecto formativo das casas subterrâneas encontradas nessa região.

$\mathrm{Na}$ década de 90 , houve uma retomada do interesse acadêmico nesse tema no Rio Grande do Sul, com a dissertação de mestrado de José Reis (Reis 1997), os trabalhos do Projeto Vacaria coordenados por Schmitz (Schmitz et alii 1999, 2001), o projeto de doutorado realizado por Copé (Copé; Saldanha 1999 , 2001), assim como a recente descoberta e escavação por Neli Machado e Saul Milder apresentada no colóquio. Essa retomada propiciou novos questionamentos, novas abordagens tanto do ponto de vista teórico quanto metodológico, e um dos momentos de discussão ocorreu durante o XI Congresso da SAB, realizado em setembro de 2001, na Comunicação Temática sobre casas subterrânes.

O Colóquio foi organizado com a finalidade de buscar um intercâmbio de informações sobre o assunto, com pesquisadores que estejam trabalhando com casas subterrâneas na atualidade. $O$ propósito desse encontro foi proporcionar mais tempo para as discussões, para a troca de informações, o que não encontra espaço em grandes congressos. 
As apresentações e discussões obedeceram ao seguinte cronograma:

\section{$15 / 08 / 2002$}

Estudo de uma "casa subterrânea" na bacia do rio Ribeira de Iguape, São Paulo. Marisa Coutinho Afonso (Museu de Arqueologia e Etnologia/USP)

"Casas Subterrâneas" e Feições

Doliniformes no Alto Paranapanema (SP). Luciane Miwa Kamase (Museu de Arqueologia e Etnologia/USP)

Salvamento Arqueológico na Usina Hidrelétrica de Campos Novos, Campos Novos, SC. Marco Aurélio Nadal De Masi (UNISUL)

Em Busca de um Sistema de Assentamento no Planalto Gaúcho: Escavações no Sítio $R S$-AN-03 Silvia Moehleke Copé; João Saldanha (Núcleo de Pesquisas Arqueológicas/ UFRGS)

Levantamento Arqueológico no Vale do Taquari. Neli T. Galarce Machado (Setor de Arqueologia/UNIVATES)

Estratigrafia e possibilidades de análise físico-química dos sedimentos das casas subterrâneas - Ilópolis. Saul Eduardo Seiguer Milder (Laboratório de Estudos e Pesquisas Arqueológicas/UFSM)

\section{$16 / 08 / 2002$}

O Projeto Vacaria, dados e resultados gerais. Pedro Ignacio Schmitz (Instituto Anchietano de Pesquisas/UNISINOS)

O material lítico e cerâmico (Projeto Vacaria). Jairo H. Rogge (Instituto Anchietano de Pesquisas/UNISINOS)

O abrigo funerário (Projeto Vacaria). Glória Demamman (Instituto Anchietano de Pesquisas/UNISINOS)

A contribuição das pesquisas na UHE Quebra-Queixo: uma problemática dos assentamentos em casas subterrâneas no extremo oeste catarinense. Ana Lucia Herberts-Scientia Ambiental

Durante o Colóquio discutiu-se sobre métodos de datação e sobre as idades dos sítios, metodologias utilizadas em campo para identificação de casas subterrâneas, depressões naturais e depressões antrópicas, distribuição de material tanto nas áreas internas quanto nas externas das casas, função das casas, entre outros temas.

As exposições e discussões mostraram que, ao contrário do que ocorre no Sul do país, a problemática encontrada em São Paulo refere-se ainda a um trabalho de base, faz-se necessário diferenciar as depressões provocadas por processos naturais, conhecidos como dolinas, que muitas vezes podem ser confundidas com as casas subterrâneas.

\section{Referências bibliográficas}

AFONSO, M.C

1997 Levantamento do Patrimônio Arqueológico na Área da Duplicação da Rodovia Régis Bittencourt (BR-116) no Estado de São Paulo. Relatório Final. Museu de Arqueologia e Etnologia. FFLCH/USP.

ARAUJO, A.G.M.

1995 Levantamento Arqueológico da área Alto Taquari, Estado de São Paulo, com ênfase na Abordagem dos Sítios Líticos. Dissertação de Mestrado. Museu de Arqueologia e Etnologia. FFLCH/USP.

2001 Teoria e Método em Arqueologia Regional: um estudo de caso no Alto Paranapanema, Estado de São Paulo. Tese de Doutorado. Museu de Arqueologia e Etnologia. FFLCH / USP.
COPÉ, S.M.; SALDANHA, J.D.M.

1999 Em busca de um sistema de assentamento no planalto sul-rio-grandense: escavações no sítio RS-AN-03. Resumos da X Reunião da Sociedade de Arqueologia Brasileira, Recife: 224

2001 Novas escavações no sítio RS-AN-03, Bom Jesus, RS. Resumos da XI Reunião da Sociedade de Arqueologia Brasileira, Rio de Janeiro: 156.

DE BLASIS, P.A.D.

2000 Resgate Arqueológico no Traçado do Gasoduto Bolívia-Brasil (GASBOL) no Estado de São Paulo: Trechos IX e X (de Paulínea à Fronteira com o Paraná). Relatório Final. Museu de Arqueologia e Etnologia. FFLCH / USP. 
KAMASE, L.M.

2001 "Casas subterrâneas" no alto Paranapanema paulista: uma abordagem geoarqueológica. Resumos da XI Reunião da Sociedade de

PROUS, A. Arqueologia Brasileira, Rio de Janeiro: 180.

1979 Première information sur les maisons souterraines de l'Etat de São Paulo, Brésil. Revista de Pré-História, São Paulo, 1 (1): 127-145.

REIS, J.A. dos

1997 Para uma arqueologia dos buracos de

Recebido para publicação em 16 de outubro de 2002. bugre: do sintetizar, do problematizar, do propor. Dissertação de Mestrado. PUC-RS. Porto Alegre, RS.

SCHMITZ, P.I. et al.

1999 Vacaria: um novo projeto sobre "casas subterrâneas". Resumos da X Reunião da Sociedade de Arqueologia Brasileira, Recife: 207. SCHMITZ, P.I; ROGGE, J.H.

2001 Casas subterrãneas no Planalto Meridional. Resumos da XI Reunião da Sociedade de Arqueologia Brasileira, Rio de Janeiro: 156.

Luciane Miwa Kamase* Marisa Coutinho Afonso**

(*) Museu de Arqueologia e Etnologia da Universidade de São Paulo. Mestranda, bolsista FAPESP.

(**) Museu de Arqueologia e Etnologia da Universidade de São Paulo. 